\title{
AVALIAÇÃO DA FERRAMENTA DE TECNOLOGIA DA INFOR- MAÇÃO E COMUNICAÇÃO (TIC) UTILIZADA NO PROCESSO DE COMPRAS EM UMA IFES: PROPOSTAS DE MELHORIAS
}

EVALUATION OF THE INFORMATION AND COMMUNICATION TECHNOLOGY (ICT) TOOL USED IN THE PROCESS OF PURCHASES IN AN FEDERAL INSTITUTION OF HIGHER EDUCATION: PROPOSALS FOR IMPROVEMENTS

Fernando Negrini', Breno Augusto Diniz Pereira²

RECEBIDO EM: 17/07/2018 | ACEITO EM: 06/11/2018

DOI: DOI: $10.5902 / 2317175833711$

\section{RESUMO}

A área de compras se constitui em uma das principais atividades de qualquer instituição pública. Porém, se essas atividades não forem realizadas de forma integrada, o processo se tornará ineficiente. Dessa forma, as Tecnologias de Informação e Comunicação (TIC's) surgem como um meio para racionalizar e integrar o processo. Este trabaIho tem o objetivo de identificar os requisitos de uma ferramenta baseada em TIC que auxilie no processo de compras em uma IFES. A pesquisa teve enfoque predominantemente quantitativo, de caráter descrito, do tipo estudo de caso, e foi desenvolvida na Universidade Federal de Santa Maria. A análise dos resultados possibilitou realizar o mapeamento dos processos de compras, identificar o grau de satisfação e grau de dificuldade dos usuários na utilização das ferramentas de TIC existentes, além de identificar sugestões de melhoria nas ferramentas de TIC. Com isso, se espera melhorar o processo, contribuindo para uma gestão pública mais eficiente.

Palavras-chave: Compras Públicas. Tecnologia da Informação e Comunicação. Processo de Compras.

1 Administrador da Universidade Federal de Santa Maria (UFSM) e doutorando em Administração pelo PPGA UFSM

2 Professor Associado da Universidade Federal de Santa Maria e Coordenador do Programa de Pós-Graduação em Gestão de Organizaç̃̃es Públicas (PPGOP/CCSH/UFSM) e professor do Programa de Pós-Graduação em Âdministração (PPGA/CCSH/UFSM) 


\begin{abstract}
The purchasing area is one of the main activities of any public institution. However, if these activities are not carried out in an integrated way, the process will become inefficient. In this way, Information and Communication Technologies (ICTS) emerge as a means to rationalize and integrate the process. This work aims to identify the requirements of an ICT based tool that assists in the purchasing process in an Federal Institution of Higher Education. The research had a predominantly quantitative approach, of a described character, of the case study type, and was developed at the Federal University of Santa Maria. The analysis of the results made it possible to map the purchasing processes, identify the degree of satisfaction and degree of difficulty of users in the use of existing ICT tools, and identify suggestions for improvement in ICT tools. This is expected to improve the process, contributing to a more efficient public management.
\end{abstract}

Keywords: Public Purchases. Information and Communication Technology. Purchasing process

\title{
1 Introdução
}

As compras públicas representam um importante fator de desenvolvimento e de ação das instituições públicas para estimular transformações, uma vez que movimentam recursos estimados em 10\% do PIB brasileiro (Cattani, 2010, apud Caldas \& Nonato, 2013). Dados do Ministério do Planejamento apontam que, no ano de 2013, as compras governamentais movimentaram $R \$ 68,4$ bilhões e, entre 2008 e 2012, o número de contratações públicas apresentou um crescimento de 77\%. Em 2014, as compras governamentais movimentaram R\$ 76,56 bilhões na aquisição de bens e serviços por meio de 149.119 processos, levando-se em consideração todas as modalidades de licitação. Já no ano de 2015 as compras públicas diminuíram tanto em valor quanto em número de processos, atingindo o valor de 45,13 bilhões e 108.473 processos realizados.

Nas universidades públicas brasileiras esse cenário de grande representação das compras no orçamento se repete, em especial nos últimos anos, em que se tem visto várias reestruturações, criação de novos cursos, ampliação de vagas aos alunos, reformas universitárias e novas formas de ensino, como o ensino a distância, por exemplo, demandando mais materiais permanentes, material de consumo e serviços. Na Universidade Federal de Santa Maria (UFSM), com a adesão ao Programa de Apoio a Planos de Reestruturação e Expansão das Universidades Federais (REUNI), novos cursos foram criados gerando demanda por inúmeros materiais para dar suporte às atividades.

$\mathrm{Na}$ UFSM, considerando as despesas totais de todas as modalidades de licitação, contratações diretas, e regime de execução especial, o valor liquidado, no ano de 2013 , foi de $R \$ 71.732 .554,07$, no ano de 2014 , foi de $R \$$ $77.583 .364,63$, e no ano de 2015 , foi de $R \$ 113$. 819.479,70. Em termos percentuais, estes valores representaram, no ano de $2013,9,32 \%$ das despesas totais por modalidade de contratação, no ano de 2014 , representaram 9,18\%, e no ano de 2015, 10,15\%. (Universidade Federal de Santa Maria [UFSM], 2016). 
Dados como esse demonstram a importância que as atividades de compras têm para o funcionamento de qualquer instituição pública. Se as compras não forem realizadas de forma adequada, situações como desabastecimento ou atraso no fornecimento de bens ou serviços poderão gerar problemas ao desenvolvimento das atividades institucionais, meio e fim.

A administração pública necessita de instrumentos que possam viabilizar a consecução dos seus interesses e, para tanto, há a necessidade de realizar obras, contratar serviços, efetuar compras e locar bens. Desta forma, um bom processo de compras é de fundamental importância para que os procedimentos de contratação sejam efetivados de forma correta, eficientes e integrados, caso contrário, as contratações serão tumultuadas porque a tendência é atuar de forma improvisada (Santos, 2013).

Nessa mesma lógica de pensamento Tridapalli, Fernandes e Machado (2011) afirmam que o planejamento e a execução de compras são preocupações fundamentais dos gestores públicos comprometidos com a eficiência e eficácia, e, para estudiosos dentro do governo, exigindo estudos para permitir aos muitos organismos a possibilidade de implantação de sistemas, para meIhoria do seu desempenho na gestão fiscal.

Para alcançar tais objetivos, existe um grande número de atividades que devem ser desenvolvidas. Conforme Batista e Maldonado (2008), no processo formal administrativo de compras vários documentos são inseridos, como autorizações, pedidos, levantamentos, cotações, documentos de habilitação, notas de empenho e pagamentos que, conjuntamente, irão compor o fluxo administrativo do processo de compras. Contudo, se essas atividades não forem realizadas de forma planejada, integrada e clara, o processo se tornará ineficiente, prejudicando todas as atividades da instituição.

Diante deste contexto, o uso de tecnologias de informação e comunicação traz benefícios às organizações, a exemplo de melhorias na integração das etapas de um processo, redução de custos operacionais, inovação em serviços, produtos e processos, integração e compartilhamento de recursos, melhorias na comunicação, dentre outras vantagens competitivas (Bahiense, 2002; Fernandes, 2005; O'Brien, 2006).

O presente trabalho tem o objetivo de apresentar uma proposta de meIhoria na ferramenta de Tecnologia de Informação e Comunicação que auxilia, atualmente, no processo de compras da UFSM. A ideia de propor um modelo de ferramenta de tecnologia da informação e comunicação justifica-se pela inexistência de um sistema integrado, que auxilie as unidades da instituição na execução e acompanhamento das etapas dos processos de compras, e na comunicação entre as unidades envolvidas no processo. Além disso, não há na UFSM uma avaliação do grau de satisfação dos usuários finais em relação à qualidade ou conformidade dos produtos ou serviços adquiridos, e em relação às ferramentas de TIC utilizadas no processo de compras da Instituição. 


\section{Referencial teórico}

A administração de materiais vem se destacando como um ponto importante na gestão das organizações públicas e privadas. A escassez de recursos no setor público enseja a formação de melhores e mais eficazes recursos gerenciais. A pressão faz-se por serviços cada vez melhores a custos menores. Diante desse contexto, a função compras assume papel verdadeiramente estratégico nos negócios de hoje em face do volume de recursos, principalmente financeiros, envolvidos, deixando cada vez mais para trás a visão preconceituosa de que era uma atividade burocrática e repetitiva, um centro de despesas e não um centro de lucros (Martins \& Alt, 2006).

Conforme Dias (2008), a função compras é um segmento essencial da administração de materiais ou suprimentos, que tem por finalidade suprir as necessidades de materiais ou serviços, planejá-las quantitativamente e satisfazê-las no momento certo com quantidades corretas. Compras é, portanto, uma operação da área de materiais, muito importante entre as que compõem o processo de suprimento.

Saldanha (2006) define a função compras da seguinte maneira: "o conceito de compras no setor público envolve todo o processo de localização de fornecedores, fontes de suprimento, consulta, escolha e aquisição de materiais por meio de licitações que envolvem quantidade, qualidade, preço (condições de pagamento, desconto), prazo de entrega, transporte, bem como o acompanhamento de processo perante o fornecedor escolhido e o recebimento do material para inspecionar e garantir o fornecimento dentro das especificações solicitadas".

Já Martins e Alt (2006) ressaltam que a função compras evoluiu e o posicionamento atual é diferente do modelo tradicional como era tratada antigamente. Hoje, a função compras é vista como parte do processo de logística, ou seja, como parte integrante da cadeia de suprimentos e não apenas como função burocrática voltada apenas para a transação em si.

Nos órgãos e nas entidades públicas, as compras devem ser realizadas de acordo com a legislação aplicável às compras públicas, ou seja, de acordo com a Lei 8.666/1993, Lei das Licitações, em conformidade com os princípios básicos da legalidade, da impessoalidade, da moralidade, da igualdade, da publicidade, da probidade administrativa, da vinculação ao instrumento convocatório, do julgamento objetivo e dos que Ihes são correlatos (Lei 8.666, 1993). Com ressalvas de algumas hipóteses legais, as compras serão necessariamente precedidas de licitação, tendo em vista o dinheiro e o interesse público que está em jogo. Por isso, os compradores públicos não podem agir livremente, mas sim, de acordo com a lei. As exceções à obrigação de licitar estão previstas na Lei $n^{\circ} 8.666 / 1993$ : inexigibilidade de licitação, quando, por algum motivo, não é viável a competição entre os licitantes, e a dispensa de licitação, quando, de forma diversa, existe a viabilidade em se realizar um procedimento licitatório, mas, em função de motivos específicos, a administração não irá realizá-la. 
Knoplock (2012) define licitações como procedimentos administrativos através dos quais a administração seleciona a proposta mais vantajosa para uma contratação, oferecendo condições iguais a todos os participantes, em que se devem observar diversos princípios. A definição do autor vai ao encontro do que consta no artigo $3^{\circ}$ da Lei $n^{\circ} 8.666 / 1993$, a qual conceitua licitação como o procedimento destinado a garantir a observância do princípio constitucional da isonomia e busca selecionar a proposta mais vantajosa para a administração.

A Lei $n^{\circ} 8.666 / 1993$ dispõe, em seu artigo 22, que são modalidades de licitação a concorrência, a tomada de preços, o convite, o concurso e o leilão. Cada uma dessas modalidades se presta a contratações específicas, tendo suas próprias características (Knoplock, 2012). A seguir a descrição das modalidades de licitação:

- Concorrência: conforme o $\S 1^{\circ}$ do artigo 22 da Lei $n^{\circ} 8.666 / 1993$, concorrência é a modalidade de licitação entre quaisquer interessados que, na fase inicial de habilitação preliminar, comprovem possuir os requisitos mínimos de qualificação exigidos no edital para execução de seu objeto.

- Tomada de preços: conforme o § $2^{\circ}$ do artigo 22 da Lei $n^{\circ} 8.666 / 1993$, tomada de preços é a modalidade de licitação entre interessados devidamente cadastrados ou que atenderem a todas as condições exigidas para o cadastramento até o terceiro dia anterior à data do recebimento das propostas, observada a necessária qualificação.

- Convite: conforme o $\S 3^{\circ}$ do artigo 22 da Lei $n^{\circ} 8.666 / 1993$, convite é a modalidade de licitação entre interessados do ramo pertinente ao seu objeto, cadastrados ou não, escolhidos e convidados em número mínimo de 3 pela unidade administrativa, e o estenderá aos demais cadastrados que manifestarem interesse com antecedência de 24 horas da apresentação das propostas.

- Concurso: de acordo com o $\S 4^{\circ}$ do artigo 22 da Lei $n^{\circ} 8.666 / 1993$, concurso é a modalidade de licitação entre quaisquer interessados para escolha de trabalho técnico, científico ou artístico, mediante a instituição de prêmios ou remuneração aos vencedores.

- Leilão: de acordo com o $\S 5^{\circ}$ do artigo 22 da Lei $n^{\circ} 8.666 / 1993$, leilão é a modalidade de licitação entre quaisquer interessados para a venda de bens imóveis inservíveis para a administração ou de produtos legalmente apreendidos ou penhorados, a quem oferecer o maior lance, igual ou superior ao valor da avaliação.

Além das 5 modalidades de licitação previstas na Lei $n^{\circ}$ 8.666/1993, no ano de 2002 foi instituída uma nova modalidade de licitação denominada pregão, a qual foi regulamentada pela Lei $n^{\circ} 10.520 / 2002$, aplicável à União, aos Estados, ao Distrito Federal e aos Municípios. O pregão é a modalidade de licitação que pode ser utilizada para aquisição de bens e serviços comuns, cujos padrões de desempenho e qualidade possam ser objetivamente definidos pelo edital, por meio de especificações usuais de mercado, independentemente de seu valor (Lei $\left.n^{\circ} 10.520 / 2002\right)$. Conforme Knoplock (2012), o pregão é realizado por meio de propostas e lances sucessivos dos licitantes, em sessão pública, e busca o menor preço oferecido. Nesta modalidade os licitantes en- 
tregam envelopes lacrados com suas propostas de preço. $\mathrm{O}$ licitante que oferecer o menor preço, e os que oferecerem preços até $10 \%$ superiores àquele, são chamados a oferecerem lances verbais sucessivos e em valor decrescente, até a escolha do menor preço.

Em 2005, foi regulamentado o pregão eletrônico, através do Decreto $n^{\circ}$ 5.450/2005. O pregão, na forma eletrônica, como modalidade de licitação do tipo menor preço, realizar-se-á quando a disputa pelo fornecimento de bens ou serviços comuns for feita a distância, em sessão pública, por meio de sistema que promova a comunicação pela internet (Decreto $n^{\circ} 5.450 / 2005$; Knoplock, 2012).

Nesse sentido, algumas iniciativas de inovação estão sendo desenvolvidas nas compras públicas, a exemplo das licitações em meio eletrônico. Conforme Fernandes (2005), as transações eletrônicas do tipo B2G (Business-toGovernment) poderão induzir a reestruturação nos mercados fornecedores governamentais, em especial, por meio da redução dos custos de transação peculiares ao fornecimento para governos, a exemplo do cumprimento de normas e legislação complexas, e da maior dificuldade de acesso à informação.

As inovações promovidas pelo Governo através do desenvolvimento de ações como o portal web Compras Governamentais (www.comprasgovernamentais.gov.br), sistema de registro de preço e criação de uma nova modalidade de licitação, pregão na forma eletrônica, vêm proporcionando a desburocratização e celeridade aos processos de aquisição de bens e contratação de serviços públicos (Fernandes, 2005). Tais inovações e decorrentes melhorias obtidas são proporcionadas, em grande parte, pelo uso de ferramentas de tecnologia da informação e comunicação, em especial a internet.

A tecnologia da informação e comunicação nos tempos atuais é um componente que está presente em toda inovação dos processos organizacionais, sendo essencial para facilitar a vida dos usuários, permitindo interação entre toda estrutura organizacional e possibilitando o desenvolvimento de ferramentas que deixem todo processo mais claro e dinâmico.

Conforme Tridapalli, et al. (2011), observa-se que organizações públicas de muitos países estão fazendo esforços no sentido de prover aos cidadãos uma entrada na sociedade da informação. Um dos esforços mais promissores é o chamado "governo eletrônico", que consiste em disponibilizar serviços governamentais, sejam eles internos ou externos, utilizando-se os modernos instrumentos de tecnologia da informação ( $\mathrm{Tl}$ ), mais especificamente a internet. Nesse sentido, as tecnologias da informação têm se mostrado uma importante ferramenta para melhoria da qualidade e aumento da produtividade dos processos que compõem a cadeia de suprimentos (Bertaglia, 2009).

Desse contexto pode ser vislumbrada a perspectiva do processo, visando repensar o modus operandi dos processos produtivos existentes no governo, em suas várias esferas, tais como os processos de licitação para compras, o e-procurement (Tridapalli et al., 2011). Para Fernandes (2005), as transações eletrônicas compreendem dimensões que extrapolam as transações comerciais stricto sensu 
e tem sido entendido como abrangendo o suporte a todo tipo de transação de negócio que utilize infraestrutura digital, o que envolve as diversas dimensões da operação de uma organização. Dessa forma, está presente em todas as fases de uma transação comercial, inclusive antes e posteriormente à venda.

O conceito de tecnologia da informação, para Batista (2006, p.59), pode ser definido como "todo e qualquer dispositivo que tenha capacidade para tratar dados e/ou informações, tanto de forma sistêmica como esporádica, independentemente da maneira como é aplicada". A tecnologia da informação é conhecida como o conjunto de hardware (equipamentos e acessórios), softwares (programas, utilitários, etc) e firmware (circuitos integrados de alguns equipamentos que possuem programas internos para determinadas atividades). O'Brien (2006) conceitua tecnologia da informação de forma muito semelhante, como sendo o conjunto de hardwares, softwares de computador, Internet, redes de telecomunicações, técnicas de administração de dados, que auxiliam no tratamento de dados.

Para Rezende e Abreu (2001), tecnologia da informação são recursos tecnológicos e computacionais para geração e uso da informação. Complementando esse conceito, a tecnologia da informação está fundamentada nos componentes: hardware e seus componentes periféricos, software e seus recursos, sistemas de telecomunicações, gestão de dados e informações. Conforme o autor, todos esses componentes interagem e necessitam do componente fundamental que é o recurso humano, peopleware. Embora conceitualmente não faça parte da tecnologia da informação, sem ele essa tecnologia não teria funcionalidade.

Um sistema baseado em tecnologia da informação, para ter qualidade, deve ser totalmente racional, planejado e ter as seguintes características: ser um sistema sem uma quantidade excessiva de formulários; ser um sistema não burocrático; possuir procedimentos lógicos, diretos e racionais; e possuir meios de processamentos adequados à atividade em questão (Batista, 2006).

Neste trabalho, será adotado o seguinte conceito para o termo tecnologia da informação e comunicação: são os recursos tecnológicos e computacionais com capacidade para tratar dados e/ou informações.

Fernandes (2005) salienta os benefícios obtidos pelo uso de tecnologia da informação e comunicação nas compras governamentais, em que a disseminação de ferramentas eletrônicas de gestão afeta, em especial, o processo de contratação, gerando impactos de redução de custos, com implicações também de incremento da competição entre os fornecedores. Tratando especificamente do setor público, Silveira (2002) destaca que aspectos como cooperação, convergência e integração das redes e dos sistemas de informação do governo devem ser utilizados e ampliados a fim de racionalizar os recursos públicos. Além disso, ressalta-se a produtividade e o ganho em eficiência que a integração e o uso intenso da internet proporcionam. Para o autor, o desafio a ser vencido é manter a simplicidade e, ao mesmo tempo, a funcionalidade, tendo sempre em vista que o interesse central é o atendimento das necessidades do cidadão. 
Nas instituições de ensino as tecnologias da informação e comunicação são bastante aplicadas na área de educação, ensino e aprendizagem. Conforme Kenski (2007), a educação e a tecnologia são indissociáveis, sendo que esta vem provocando modificações na maneira de fazer e pensar a educação. Exemplos de TIC's utilizadas em instituições de ensino superior são as ferramentas utilizadas no ensino a distância (EaD), através da criação de ambientes virtuais com recursos que permitem a troca de conhecimentos entre os usuários, independe da localização geográfica (Almeida, 2002). Essas TIC's vêm com facilidades de design e produção sofisticados, rápida emissão e distribuição de conteúdos, interação com informações, recursos e pessoas, permitindo às instituições assumir diversas abordagens.

\section{Método de pesquisa}

Quanto à abordagem do problema a pesquisa predominantemente teve enfoque quantitativo. $O$ estudo realizado foi classificado como sendo de caráter descritivo, quando se considera o atendimento aos objetivos. Essa classificação considera que foi realizada uma análise descritiva dos dados obtidos através do emprego das técnicas e procedimentos metodológicos a seguir descritos, e contém ações. O método de pesquisa adotado é o estudo de caso. Entendeu-se que era o método mais adequado para a pesquisa, visto que o trabalho buscou propor um modelo de ferramenta de Tecnologia de Informação e Comunicação que auxiliasse no processo de compras da UFSM. Tomou-se como base o resultado da análise documental, da entrevista com o servidor responsável pela coordenação, direção e execução das atividades relativas a compras e a licitações destinadas à aquisição de material, contratações de serviços da universidade, e dos questionários aplicados aos usuários das ferramentas de Tecnologia de Informação e Comunicação relacionadas às compras, utilizadas na Instituição.

O trabalho foi desenvolvido na Universidade Federal de Santa Maria (UFSM), a qual é uma Instituição Federal de Ensino Superior, constituída como Autarquia Especial vinculada ao Ministério da Educação, e fundada em 14 de dezembro de 1960, na cidade de Santa Maria, interior do estado do Rio Grande do Sul. As principais atividades da Instituição estão relacionadas ao ensino, pesquisa e extensão. Dados de 2016 revelam que a instituição emprega 4738 servidores em cargos efetivos, sendo 1.970 docentes e 2.768 técnico-administrativos em educação, e possui 29.326 alunos regularmente matriculados em cursos de graduação, pós-graduação, ensino médio, pós-médio e ensino técnico, nas modalidades presencial e Ensino a Distância (EaD) (Universidade Federal de Santa Maria, 2016).

O trabalho focou na área de compras institucionais, envolvendo os setores responsáveis diretamente pelas solicitações de compras dos departamentos das Unidades Universitárias, dos Programas de Pós-Graduação, das Pró-Reito- 
rias, dos Órgãos Executivos e dos Órgãos Suplementares da instituição. Além desses, o trabalho foi desenvolvido também no Departamento de Material e Patrimônio (DEMAPA) da UFSM, o qual é responsável por coordenar, dirigir e executar as atividades relativas a licitações, dispensas e inexigibilidades destinadas à aquisição de material, contratações de serviços e importações, controle patrimonial de bens móveis e imóveis, manutenção de estoques de material de consumo e sua distribuição a todas as subunidades.

A análise documental foi realizada em fontes estatísticas e em documentos e relatórios emitidos pela Instituição. Foi entrevistada uma servidora do DEMAPA, responsável pelo controle do fluxo da atividade de compras da UFSM, a qual foi escolhida de forma intencional, e justificou-se por ser uma profissional especializada, com experiência na área de compras, e por exercer um cargo estratégico nessa área. Foram aplicados questionários aos responsáveis pelas solicitações de compras, acompanhamento das licitações, dispensas e inexigibilidades e controle do registro de preços das Unidades Universitárias, Pró Reitorias, Órgãos Executivos, e Órgãos Suplementares da UFSM.

O universo da pesquisa foi formado por 140 respondentes, estratificados dentro dos seguintes subconjuntos homogêneos: 09 Pró Reitorias, 08 Órgãos Executivos, 12 Órgãos Suplementares, e 11 Unidades Universitárias (11 direções de Unidade, 74 departamentos e 26 Programa de Pós-Graduação). Nesse contexto, foi calculada uma amostra de 103 respondentes, a qual considerou uma margem de erro de $5 \%$ e nível de confiança de $95 \%$.

Os dados obtidos na entrevista foram analisados através da técnica de análise de conteúdo. Em relação aos dados obtidos com a aplicação dos questionários, foi realizada a análise descritiva univariada, que consistiu na análise estatística descritiva das variáveis, separadamente. Os dados foram analisados com o auxílio do software $I B M^{\circledR}$ SPSS ${ }^{\circledast}$ Statistics Base, o qual permite a realização das análises estatísticas, contribuindo para a caracterização e resumo dos dados.

\section{Apresentação e discussão dos resultados}

Os processos de compras existentes na Universidade Federal de Santa Maria são os procedimentos utilizados para aquisição de bens e serviços de qualquer natureza, a fim de dar suporte às atividades da Instituição, sejam atividades didáticas ou administrativas. Qualquer aquisição ou contratação deve ser realizada através de um dos processos de compras existentes. Por se tratar de uma Instituição pertencente à administração pública, as compras realizadas pela UFSM seguem estritamente as disposições legais aplicáveis, a exemplo da Lei $n^{\circ}$ 8.666/1993, Decreto 5.450/2005 e Decreto 7.892/2013, as quais regulamentam as normas de licitações e contratos da administração pública, a modalidade de licitação pregão na forma eletrônica, e o sistema de registro de preços, respectivamente.

$\mathrm{Na}$ Instituição em estudo são realizados os seguintes processos de com- 
pras: Licitação - Modalidade Pregão Eletrônico - Registro de Preço; Licitação - Modalidades Pregão, Concorrência, Tomada de Preços e Convite; Dispensa de Licitação e Inexigibilidade; Suprimento de fundos; Adesão. Esses processos são realizados através de fluxos de atividades específicas, com seus respectivos responsáveis, movimentação de documentos e utilização de sistemas. Com exceção das aquisições via suprimento de fundos e adesão, os processos de compras são executados com o auxílio da ferramenta de tecnologia de informação e comunicação, denominada Sistema de Informações Educacionais (SIE).

O Sistema de Informações Educacionais (SIE) é uma ferramenta de TIC utilizada pela UFSM nas atividades de compras, orçamento, gestão de pessoas, atividades didáticas, dentre outras funções. Consiste em um programa desenvolvido pelo Centro de Processamento de Dados da universidade, onde são inseridas as informações referentes às solicitações de compras, como a descrição dos itens, preços orçados, natureza de despesa, códigos dos produtos, unidade gestora, dentre outras. O programa somente é acessado por servidores autorizados, e contém aplicações que permitem aos usuários inserir informações referentes às solicitações de compras, acompanhar o andamento das mesmas, e consultar os materiais já licitados e disponíveis para empenho.

Com base na entrevista realizada e na análise documental, foi possível descrever os processos de compras existentes na Instituição.

A Licitação na Modalidade Pregão Eletrônico - Registro de Preço se inicia com o surgimento da demanda pela unidade solicitante, a qual deve descrever os itens que irão para licitação, obter orçamentos para balizar os preços no certame licitatório, inserir os dados da solicitação no SIE, e tramitar para o departamento responsável pelas análises das solicitações e elaboração do edital. Após, a licitação é realizada on-line no portal de compras do Governo Federal, pelo departamento específico para tal finalidade. Com o término da licitação, os itens solicitados ficam disponíveis para empenho no Sistema de Registro de Preços, pelo período de até um ano.

O processo de Licitação - Modalidades Pregão, Concorrência, Tomada de Preços e Convite é semelhante ao da modalidade Pregão Eletrônico - Registro de Preço, com exceção da forma de realização da licitação, a qual nas modalidades Pregão, Concorrência, Tomada de Preços e Convite é realizada de forma presencial, enquanto que o Pregão Eletrônico é realizado a distância (online). Difere também em relação à obrigatoriedade de aquisição dos materiais após o término da licitação, em que nas modalidades Pregão, Concorrência, Tomada de Preços e Convite há a obrigatoriedade de aquisição dos materiais, enquanto que nas licitações do tipo Registro de Preço não há obrigatoriedade na aquisição dos itens licitados.

$\mathrm{Na}$ Dispensa de Licitação e Inexigibilidade o processo tem início com a demanda pela unidade solicitante, inserção dos dados no SIE, e encaminhamento para o departamento responsável pela análise da solicitação. Após análise, esse departamento realiza o empenho, sem a realização da licitação. 
No Suprimento de Fundos as compras são realizadas por meio de um cartão, com liberação mensal de saldo para as aquisições, as quais são limitadas a casos de urgência e emergência, e a materiais de consumo. A Adesão é o processo no qual a Instituição adere a uma licitação de outro órgão. Este processo se inicia com a demanda de uma unidade, juntamente de documentos, encaminhamento para o setor responsável para oficializar a adesão, disponibilização do (s) material (ias) no Sistema de Registro de Preço, e empenho. Ressalta-se que nos processos de Suprimento de Fundos e Adesão não há a utilização da ferramenta de tecnologia de informação e comunicação SIE.

Após a descrição dos processos de compras utilizados na UFSM, os dados coletados foram interpretados visando identificar as dificuldades enfrentadas e sugestões de melhorias na utilização das ferramentas de Tecnologia de Informação e Comunicação (TIC), além de apresentar um modelo de ferramenta de TIC que auxilie no processo de compras da Instituição. Os principais módulos de compras do Sistema de Informações Educacionais (SIE) foram avaliados pelos usuários.

Em relação à avaliação do módulo de solicitação de licitações do SIE, os servidores responderam questões relacionadas à facilidade de utilização do referido módulo, à clareza e simplicidade no preenchimento dos campos, à facilidade de utilização das ferramentas de busca, à flexibilidade e facilidade para realizar alterações durante o uso da aplicação, à necessidade ou não, de preenchimento de todos os campos, à estruturação lógica e compreensível do módulo, e ao layout. Os respondentes indicaram seu grau de concordância de acordo com a escala: 1 = Discordo Totalmente, $2=$ Discordo, $3=$ Neutro, $4=$ Concordo, 5 = Concordo Totalmente.

A solicitação de compras é a etapa do cadastramento no SIE, na qual devem ser inseridos dados referentes às solicitações, como a unidade gestora, natureza de despesa, descrição do item, valor do item, código reduzido do item, dentre outros.

Tabela 1 - Grau de concordância em relação à aplicação do SIE - Solicitação de compra

\begin{tabular}{|l|l|}
\hline Questão & Média \\
\hline O layout da aplicação é atrativo? & 2,37 \\
\hline A aplicação é flexível e fácil para realizar alterações nos campos preenchidos? & 2,80 \\
\hline As ferramentas de busca para preenchimento dos campos facilitam a utilização? & 2,84 \\
\hline O preenchimento dos campos é simples e claro? & 2,99 \\
\hline A aplicação do SIE “Solicitação de Compra"- 5.5.03 está estruturada em uma sequência lógica e compreensível? & 3,10 \\
\hline A aplicação do SIE "Solicitação de Compra" - 5.5.03 é de fácil utilização? & 3,16 \\
\hline Todas as informações que devem ser preenchidas são necessárias? & 3,53 \\
\hline Elaborado pelo autor & \\
\hline
\end{tabular}


Pela análise da Tabela 1 - Grau de concordância em relação à aplicação do SIE - Solicitação de compra, pode-se observar que todas as questões levantadas obtiveram média inferior a 4, o que representa neutralidade ou insatisfação em relação às variáveis pesquisadas. As variáveis referentes ao "layout atrativo da aplicação", "flexibilidade/facilidade de alterações nos campos", "ferramentas de busca para preenchimento dos campos" e "simplicidade/clareza no preenchimento dos campos" obtiveram médias que variaram entre 2,37 e 2,99, se enquadrando na escala 2, que significa discordar das afirmativas das questões. Já as variáveis "estrutura lógica e compreensível da aplicação", "facilidade de utilização da aplicação" e "necessidade de preenchimento de todas as informações" obtiveram médias que foram de 3,10 a 3,53, as quais se enquadram na escala "Neutro" em relação às questões. Pelos resultados observados constatou-se que, no geral, há insatisfação em relação a todos os tópicos pesquisados.

Os resultados aqui expostos vão ao encontro do estudo realizado por Queiroz et al (2017) sobre a percepção de usuários na utilização de ferramentas de TIC. Na aplicação de um modelo de mensuração da satisfação dos usuários de um sistema de informação acadêmico de uma universidade, identificou-se que os fatores utilidade percebida, que considera variáveis como facilidade de acessar o sistema, layout, clareza, sequência lógica das operações feitas, e quantidade de informações exibidas na tela, teve maior impacto na determinação da satisfação dos usuários, seguido pelos fatores qualidade do sistema, que contém variáveis como simplicidade de registro, padronização da navegação, informações dispostas de forma direta, e qualidade da informação, a qual contém variáveis como informações abrangentes, informações completas, informações de fácil entendimento, e informações seguras. Percebe-se que o layout, a simplicidade, a facilidade de acessar informações, a facilidade no preenchimento de campos, e a clareza das informações dispostas são variáveis importantes que interferem no grau de satisfação dos usuários de TIC's. Ferramentas de TIC com interfaces amigáveis, contendo informações claras, com campos de preenchimento simples, melhoram a usabilidade de um sistema, evitando retrabalho e interpretações erradas. Lemos et al (2004) citam a importância da simplicidade da interface gráfica em portais web, a qual permite a interação do ambiente da informação digital com o usuário. Nesse sentido, a importância da interface gráfica para os portais web é de traduzir, de maneira mais ágil, o conteúdo disponibilizado, além de simplificar a usabilidade do sistema (LEMOS et al, 2004). Assim, o desenvolvimento de um sistema que comtemple essas considerações é de grande importância para uma melhor integração entre a tecnologia e as pessoas.

Neste trabalho, se teve a preocupação de conhecer a opinião dos servidores que utilizam as ferramentas de Tecnologia da Informação e Comunicação (TIC), a fim de identificar o seu grau de satisfação, grau de dificuldades e sugestões de melhoria, em relação às TICs existentes na UFSM. Com isso, os servidores puderam contribuir com sugestões para melhorar o sistema utilizado pela instituição. 
AVALIAÇÃO DA FERRAMENTA DE TECNOLOGIA DA INFORMAÇÃO E COMUNICAÇÃO (TIC) UTILIZADA NO PROCESSO DE COMPRAS EM UMA IFES: PROPOSTAS DE MELHORIAS

Tabela 2 - Sugestões de melhoria para a aplicação do SIE - Solicitação de compra

\begin{tabular}{|l|l|}
\hline Sugestão & $N^{0}$ de citações \\
\hline Inclusão de campos de preenchimento autoexplicativos & 11 \\
\hline Melhorias na localização e identificação dos códigos dos itens & 10 \\
\hline Facilitar a localização dos itens pela descrição & 07 \\
\hline Inclusão de catálogo padronizado & 06 \\
\hline Tornar o sistema mais intuitivo e amigável & 06 \\
\hline Melhorias no campo de preenchimento da classificação de despesa & 06 \\
\hline Migrar do SIE para o ambiente web & 05 \\
\hline Eliminação de campos de preenchimento desnecessários & 03 \\
\hline Etaborado pelo duto & 06 \\
\hline
\end{tabular}

Conforme a Tabela 2, as principais sugestões apresentadas são em relação a melhorias nas ferramentas de localização e no preenchimento de campos. A inclusão de campos de preenchimento autoexplicativos e melhorias no campo de preenchimento da classificação da despesa tiveram, juntas, 17 citações, o que revela a dificuldade dos usuários no preenchimento dos campos da ferramenta de TIC analisada. As dificuldades relatadas demonstraram que os usuários não se sentem seguros ao inserir informações no sistema, sendo necessário recorrer a outras fontes, a exemplo de manuais técnicos ofertados pela UFSM, ou sítios governamentais. As melhorias na localização e identificação dos códigos dos itens foram citadas por 10 participantes da pesquisa, o que revela que as ferramentas de buscas existentes nesse módulo do SIE não facilitam a localização de informações, seja por meio dos códigos dos itens ou da descrição dos mesmos. Padronização, e sistema mais intuitivo e amigável também foram citados como sugestões de melhorias para a ferramenta analisada.

Conforme Goto e Ramos (2013), em seu artigo intitulado "Portais das Universidades Federais Brasileiras: uma análise a partir das cartilhas do e-PWG", cujo objetivo foi analisar ferramenta de TIC em 10 Instituições Federais de Ensino Superior, a facilidade de uso e o conteúdo presentes nestas ferramentas, foram avaliadas positivamente. Os resultados indicam que, em relação à facilidade de uso, o usuário está sendo considerado como foco no planejamento dos portais eletrônicos. E em relação ao conteúdo presente nas ferramentas de TIC, apresentam-se em sua totalidade os principais assuntos de interesse do usuário. Os resultados obtidos no estudo de Goto e Ramos (2013) contrastam com os resultados deste trabalho, em que os usuários consideraram insatisfatória a facilidade de utilização do sistema, questões referentes à localização de informações necessárias, e sistema mais intuitivo e amigável. Com isso, ressalta-se a importância do desenvolvimento de uma ferramenta que considere as reais necessidades dos usuários e da Instituição, em termos de confiabilidade, usabilidade, conteúdo, acessibilidade e transparência.

Da Costa (2001) reforça a ideia de que um portal web deve proporcionar ao usuário uma experiência que inspire confiança, com dados e informações cla- 
ras, que permitam ao usuário obter e inserir dados de forma segura. Além disso, o autor destaca a importância da padronização das informações devido à grande quantidade de códigos, diversidade de fontes e termos usados em um portal.

Outra etapa do processo de compras é o controle do Registro de Preço, que se dá após a realização das licitações. Nesta parte do trabalho, os participantes da pesquisa avaliaram as aplicações do SIE que disponibilizam os relatórios de registro de preços. Os servidores responderam questões referentes à facilidade de utilização das aplicações, aos mecanismos de busca existentes e disponíveis aos usuários da aplicação, ao layout dos relatórios emitidos pela aplicação, ao conteúdo de informações necessárias para avaliação dos itens presentes nos relatórios de registro de preço, e à facilidade de realizar pesquisas ou buscar informações sobre itens nos relatórios de registro de preço.

Tabela 3 - Grau de concordância em relação às aplicações do SIE - Registro de Preço

\begin{tabular}{|l|l|}
\hline Questão & Média \\
\hline O layout do relatório do Registro de Preço é atrativo? & 2,38 \\
\hline Os mecanismos de busca existentes nos relatórios de Registro de Preço são satisfatórios? & 2,58 \\
\hline $\begin{array}{l}\text { Você consegue realizar pesquisas de itens e buscar informações sobre materiais ou serviços } \\
\text { disponíveis no Sistema de Registro de Preço de maneira satisfatória? }\end{array}$ & 2,72 \\
\hline A aplicação do SIE que disponibiliza os relatórios de Registro de Preços é de fácil utilização? & 2,84 \\
\hline $\begin{array}{l}\text { Todas as informações necessárias para avaliação dos produtos e serviços estão presentes nos } \\
\text { relatórios dos Registro de Preço? }\end{array}$ & 2,91 \\
\hline
\end{tabular}

Elaborado pelo autor

Pela análise da Tabela 3 - Grau de concordância em relação às aplicações do SIE - Registro de Preço, observa-se que todas as questões avaliadas pelos usuários do sistema obtiveram média que variaram de 2,38 a 2,91, o que as posicionou na alternativa "Discordo". Tais constatações demonstram uma discordância da opinião dos usuários pesquisados em relação às questões. Com isso, pode-se inferir que os indivíduos estão insatisfeitos com as aplicações que estão em análise.

Em um estudo publicado por Mota, De Oliveira e De Freitas (2016), no qual foi desenvolvido e implantado um software de gestão de apoio à tomada de decisão em Secretarias Municipais de Assistência Social de alguns municípios brasileiros, o sistema implantado mescla ao mesmo tempo uma interface intuitiva com todo o instrumental necessário para seus usuários desempenharem suas funções, obtendo, assim, melhor desempenho e facilidade de utilização pelos usuários. Os benefícios obtidos podem ser traduzidos pela precisão das informações, pela geração de relatórios obrigatórios ao alcance de um clique e na visualização, por meio de gráficos e tabelas, de dados e informações claras e diretas. O desenvolvimento de uma ferramenta de TIC deve também prezar pela simplicidade e precisão das informações, a fim de evitar sua duplicidade. Esses resultados corroboram a necessidade de melhoria no sistema utilizado pela UFSM, pois de acordo com a avaliação dos usuários, variáveis como layout, mecanismo de busca existentes, facilidade de realização de pesquisas, e facilidade de utilização do sistema foram considerados insatisfatórios. 
AVALIAÇÃO DA FERRAMENTA DE TECNOLOGIA DA INFORMAÇÃO E COMUNICAÇÃO (TIC) UTILIZADA NO PROCESSO DE COMPRAS EM UMA IFES: PROPOSTAS DE MELHORIAS

Neste trabalho, as principais etapas do processo de compras da UFSM - solicitação de licitações e controle dos registros de preços - foram avaliadas pelos servidores que participaram da pesquisa. Após essa avaliação, puderam avaliar a integração entre essas etapas. Acredita-se que, se os processos de uma Instituição estão bem integrados, é possível identificar seus gargalos com maior facilidade, minimizando seus impactos. A fim de identificar a percepção dos servidores em relação à integração dos processos já discutidos, os indivíduos avaliaram a integração entre as etapas de solicitação de licitação, acompanhamento das licitações e controle do registro de preços, seguindo a escala: 1 = Ótima, 2 = Boa, 3 = Regular, 4 = Ruim, 5 = Péssima, 6 = Não sei.

A média obtida foi de 3,02, se enquadrando na opção "Regular". Uma alternativa para melhorar a integração das etapas do processo de compras é concentrar todas as etapas que são realizadas com auxílio de ferramentas de TIC em um único ambiente web, sem necessidade de utilizar diferentes aplicações dentro do sistema. A integração com o Sistema Integrado de Administração de Serviços Gerais (SIASG) também pode ser considerada uma alternativa para meIhorar a integração, porém, esse sistema não é desenvolvido pela UFSM.

Como Laudon e Laudon (2010) apresentam, a implantação de um sistema de informação deve ser planejada, articulada e integrada, de modo a atender às demandas de todos os envolvidos no processo, considerando os aspectos tecnológicos, institucionais e humanos. Os autores ressaltam também que fatores sociotécnicos relacionados aos recursos humanos - como necessidade de treinamento, falta de suporte técnico e de políticas motivacionais, e a resistência cultural à mudança - são questões a serem resolvidas para uma melhor integração das TIs disponíveis. Para Cária e Laia (2018), no que diz respeito ao processo de implantação de um sistema, este não apenas compreende a interação de diferentes atores, como também envolve o entendimento sobre a diversidade de seus papéis e objetivos. Observa-se que as discussões de implantação de software são focadas predominantemente em uma lógica tecnicista, considerando prioritariamente a tecnologia e colocando em segundo plano os aspectos humanos e organizacionais (CÁRIA e LAIA, 2018). Tais questões levantam a importância de considerar a opinião dos usuários do sistema no processo de desenvolvimento ou de melhorias das TIC's, pois os usuários serão os responsáveis pela operacionalização das ferramentas tecnológicas depois de implantadas.

A parte final do trabalho constituiu-se na elaboração de um modelo da ferramenta de Tecnologia da Informação e Comunicação, a fim de auxiliar o processo de compras da Instituição. O modelo foi elaborado com base no resultado da coleta de dados, que se constituiu na análise documental, entrevista realizada com a Diretora do Departamento de Materiais e Patrimônio (DEMAPA), e na aplicação de questionários a 105 servidores que trabalham com atividades relacionadas a compras em seus setores/departamentos/unidades.

A ferramenta de TIC proposta será composta por abas e campos de preenchimento, que buscarão a compreensão do processo, a facilidade no preen- 
chimento, a simplificação nas buscas, o layout simples, além de propor uma sequência lógica de preenchimento. $O$ modelo de ferramenta proposto procurou seguir a literatura sobre o tema, a exemplo de Reynolds e Koulopoulos (1999), os quais enfatizam que os sistemas de informação devem priorizar o fluxo de dados e o suporte às tarefas, e Batista (2006), o qual afirma que um sistema baseado em tecnologia da informação, para ter qualidade, deve ser racional, sem uma quantidade excessiva de formulários, possuir procedimentos lógicos, diretos e racionais. Da Costa (2001) salienta que tecnologias de informação baseadas na web possuem características como acessibilidade via web browsers, rapidez de distribuição, visto que não se tem preocupações com questões relacionadas ao sistema operacional das máquinas clientes, e maior facilidade e menor preço para desenvolver e manter do que sistemas client-server e mainframes, o que tornam a tecnologia web extremamente adequada para qualquer tipo de organização.

A seguir está descrita a estrutura da ferramenta.

Tabela 4 - Estrutura da ferramenta de Tecnologia de Informação e Comunicação

\begin{tabular}{|c|c|c|}
\hline Solicitação de compra & $\begin{array}{l}\text { Acompanhamento da solicitação de } \\
\text { compra }\end{array}$ & Registro de preço \\
\hline $\begin{array}{l}1 \text { - Nova solicitação } \\
2 \text { - Unidade solicitante } \\
3 \text { - Nome do solicitante } \\
4 \text { - Contato do solicitante } \\
5 \text { - Unidade Gestora } \\
6 \text { - Tipo de solicitação de compra } \\
7 \text { - Natureza de despesa } \\
8 \text { - Incluir item: } \\
\text {-Descrição do item } \\
\text {-Código do item } \\
\text {-Preço do item } \\
\text {-Quantidade } \\
\text {-Unidade de medida } \\
9 \text { - Fornecedor (somente no caso } \\
\text { de dispensa e inexigibilidade) } \\
10 \text { - Anexar orçamentos } \\
11 \text { - Justificativa da solicitação de } \\
\text { compra } \\
12 \text { - Salvar } \\
13 \text { - Corrigir } \\
14 \text { - Tramitar }\end{array}$ & $\begin{array}{l}\text { 1 - Número da solicitação (ou utilizar as } \\
\text { opções de busca) } \\
\text { - Localização atual no processo, com } \\
\text { indicação da unidade e etapa onde se } \\
\text { encontra, e representação gráfica da } \\
\text { localização no fluxo } \\
\text { - Indicação da atividade a ser realizada no } \\
\text { momento } \\
\text { - Informações sobre a licitação/dispensa/ } \\
\text { inexigibilidade } \\
\text { - Data de realização da licitação } \\
\text { - Disponibilização do edital de licitação e } \\
\text { termo de referência } \\
\text { - Situação da solicitação } \\
\text { - Informações sobre os itens nas licitações }\end{array}$ & $\begin{array}{l}\text { 1- Escolha uma das opções } \\
\text { 2 - Localizar por } \\
\text { 3 - Informações: } \\
\text { - Descrição detalhada do objeto } \\
\text { - Marca, modelo, fabricante } \\
\text { - Classificação do item: natureza de despesa e } \\
\text { código do item } \\
\text { - Dados da licitação: modalidade, número, } \\
\text { situação } \\
\text { - Número do Registro de Preço } \\
\text { - Extrato } \\
\text { - Período de vigência do Registro de Preço: data } \\
\text { de início e término } \\
\text { - Nome do fornecedor } \\
\text { - Contato do fornecedor: telefone, e-mail, } \\
\text { endereço } \\
\text { - Catálogo do produto, ou na inexistência deste, } \\
\text { imagens/fotos dos mesmos. }\end{array}$ \\
\hline
\end{tabular}


AVALIAÇÃO DA FERRAMENTA DE TECNOLOGIA DA INFORMAÇÃO E COMUNICAÇÃO (TIC) UTILIZADA NO PROCESSO DE COMPRAS EM UMA IFES: PROPOSTAS DE MELHORIAS

$\mathrm{Na}$ etapa do cadastro das solicitações no sistema atual (SIE), o modulo de solicitação de compras é composto por 05 abas e 26 campos de preenchimento, sendo que nem todos os campos são de preenchimento obrigatório. Neste trabalho, se propõe manter 14 campos de preenchimento na aba "Solicitação de compras", os quais englobam todas as informações necessárias para a realização do processo licitatório. Esta proposta vai ao encontro da opinião de Silveira (2002), o qual menciona que um dos grandes desafios dos sistemas baseados na Internet é manter a simplicidade.

Foram adicionados, aos campos de preenchimento, mecanismos de busca por diferentes categorias, a fim de facilitar a localização e seleção da opção correta. Estas funcionalidades foram incluídas nas questões sobre a localização dos itens (tanto em relação ao código quanto à especificação), localização das unidades solicitantes, unidades gestoras, e localização da natureza de despesa. Os campos de preenchimento foram simplificados, foi adicionada a opção "corrigir" antes de tramitar para a próxima etapa, e eliminados campos de preenchimento que não são necessários para o processo de compras. Foram incluídos também ícones de ajuda, contendo um tutorial e um passo a passo para esclarecer dúvidas e orientar o preenchimento dos campos. Conforme a pesquisa, $82,9 \%$ dos servidores que responderam os questionários concordam que a disponibilização de um catálogo padronizado auxiliaria nas atividades de compras. Neste sentido, sugeriu-se disponibilizar o catálogo que está sendo elaborado pelo DEMAPA, junto aos campos de preenchimento, para consulta, na localização e seleção dos códigos dos itens, descrição dos itens, natureza de despesa.

Para a formulação dos preços dos itens que são licitados foram criados espaços para inserir os valores ofertados por cada fornecedor, e o preço médio de cada item (que servirá de referência para o valor do item na licitação) será calculado automaticamente, eliminando, assim, os cálculos manuais. Os orçamentos, que no processo atual devem ser impressos, assinados e enviados fisicamente, no modelo proposto devem ser anexados no sistema, em um campo específico, e transmitidos via Internet. Assim, elimina-se a impressão e envio de papéis, gerando economia de recursos, de tempo e agilizando o processo. Da Costa (2001) argumenta que a eliminação de papéis, fichas e formulários impressos é uma das consequências imediatas da implantação de sistemas web, o que resulta em economia para a instituição onde o sistema é implantado.

Tais inserções procuram sanar as dificuldades e insatisfações dos usuários na utilização do módulo solicitação de compras. As maiores insatisfações foram em relação à localização dos itens que são cadastrados (tanto em relação a seus códigos quanto em relação à descrição), à localização da classificação de despesa, ao layout, à inflexibilidade para fazer alterações, às ferramentas de busca e ao preenchimento dos campos. Como pode ser observada na avaliação dos usuários do sistema (SIE), todos os aspectos avaliados na aplicação "Solicitação de compras" foram considerados difíceis ou neutros, em relação à sua utilização. 
Em relação à aba "Acompanhamento da solicitação de compra", foram adicionadas opções de busca por 04 diferentes critérios: palavra-chave, natureza de despesa, unidade solicitante e tipo de solicitação. Assim, será possível acompanhar qualquer solicitação realizada no âmbito da Instituição, e não somente aquelas solicitadas pela respectiva unidade. No relatório que indicia o status da solicitação foram incluídas 07 informações adicionais que não constam no atual relatório de situação da solicitação de compras fornecido pelo SIE. Através dessas melhorias, é possível obter informações específicas e também informações mais genéricas sobre o processo de compras, desde a localização ao longo do processo, até o número de itens finalizados, cancelados e desertos nas licitações.

$\mathrm{Na}$ terceira aba, "Registro de Preço", foram adicionadas 08 categorias de busca na ferramenta de localização, a fim de facilitar a seleção dos itens de acordo com diferentes critérios: listar todos os itens disponíveis para sua unidade, palavra-chave, natureza de despesa, unidade solicitante (nome ou código), fornecedor, validade do Registro de Preço, número do registro de preço, marca/modelo/fabricante. Procurou-se, com isso, sanar uma das principais fontes de insatisfação dos usuários, que é a dificuldade de localizar os objetos disponíveis, já licitados e prontos para aquisição.

No detalhamento dos objetos constantes no registro de preços foram adicionadas também 03 novas funcionalidades às já existentes, que auxiliam na avaliação dos itens pelos usuários: marca/modelo/fabricante, contato do fornecedor - telefone, e-mail, endereço - e catálogo do produto, ou na inexistência deste, imagens/fotos dos mesmos. As melhorias sugeridas se originaram das dificuldades e insatisfações relatadas na utilização dos relatórios de registro de preços, em relação ao seu layout, aos mecanismos de busca, à facilidade de utilização, e à avaliação dos itens somente com as informações constantes no relatório de registro de preço. Na pesquisa identificou-se que os usuários do sistema consideram insatisfatórios todos os aspectos avaliados referentes ao registro de preço.

As funcionalidades adicionadas foram decorrentes da colaboração dos servidores que responderam o questionário, e contribuíram com importantes sugestões de melhoria, além das sugestões obtidas na entrevista. Procurou-se propor um modelo de ferramenta de TIC a fim de melhorar o processo de compras da Instituição, indo ao encontro da opinião de $70,50 \%$ dos respondentes da pesquisa, que concordam que o desenvolvimento de um novo sistema de compras na UFSM melhoraria o processo.

O modelo proposto procurou considerar as necessidades dos usuários em alinhamento com os requisitos de usabilidade e simplicidade do sistema, e melhoria dos processos, bem como as peculiaridades do processo de compras da UFSM. O uso de ferramentas de TIC trazem benefícios às organizações, entre eles estão a redução de custos de processos, diferenciação em serviços, e inovação em processos, conforme cita O'Brien (2006). Fernandes (2005) também salienta os benefícios obtidos pelo uso de tecnologia da informação e comunicação, notadamente, a redução de custos e melhoria de processos. 
AVALIAÇÃO DA FERRAMENTA DE TECNOLOGIA DA INFORMAÇÃO E COMUNICAÇÃO (TIC) UTILIZADA NO PROCESSO DE COMPRAS EM UMA IFES: PROPOSTAS DE MELHORIAS

\section{Considerações Finais}

As atividades de compras são funções essenciais à administração, pois visam suprir as necessidades de materiais e serviços de qualquer organização. Nos órgãos e nas entidades públicas, as compras devem ser realizadas de acordo com a legislação aplicável, formada por leis, decretos e regulamentos, que normatizam como devem ser realizadas as aquisições pelos entes públicos. Com ressalvas estabelecidas em lei, as aquisições e contratações feitas por órgãos e entidades públicas são obrigatoriamente realizadas por meio de licitação, tendo em vista o interesse público.

Apesar de as compras públicas estarem alicerçadas em legislação específica, o que as tornam menos flexíveis em relação às compras realizadas pela iniciativa privada, pode-se observar iniciativas inovadoras nesse campo, a exemplo da modalidade de licitação pregão eletrônico, do sistema de registro de preços e do sítio eletrônico Compras Governamentais, os quais utilizam tecnologias de informação e comunicação (TIC) em suas atividades.

As ferramentas de TIC proporcionam vantagens às organizações, como a redução de custos e a agilização de processos. Neste sentido, este trabalho objetivou propor um modelo de ferramenta de TIC que auxilie no processo de compras da UFSM. Através da pesquisa foi possível identificar o nível de satisfação dos usuários dos módulos de compras do sistema utilizado pela UFSM, bem como obter sugestões de melhoria para o sistema e analisar o processo de compras da Instituição.

Conforme os resultados da pesquisa, constatou-se que a avaliação dos módulos do SIE, "Solicitação de compras", e "Registro de Preço", foi considerada, no geral, insatisfatória ou neutra. Os principais pontos de insatisfação foram em relação às dificuldades de localização nos campos de preenchimento, limitação das opções de busca, layout pouco atrativo e informações insuficientes nos relatórios emitidos.

A partir daí foi elaborado o modelo de uma ferramenta de TIC para a Instituição. O modelo proposto é composto por 03 abas (Solicitação de compras, Acompanhamento da solicitação de compras, Registro de Preço) contendo campos de preenchimento simplificados, ícones de ajuda, campos de busca e localização por diferentes critérios, novas informações de contato, localização da solicitação ao longo do processo, dentre outras funcionalidades.

Com isso, considerou-se que os objetivos do trabalho foram alcançados, visto que o modelo da ferramenta de TIC foi esboçado. As principais contribuições do trabalho foram: identificar os pontos críticos do processo, identificar as dificuldades e sugestões de melhorias dos usuários na utilização da ferramenta de TIC existente, bem como proporcionar o início de uma discussão de mudança da forma como são realizados os processos de solicitação de compras, acompanhamento da solicitação de compras, e registro de preços. A discussão propõe migrar essas atividades do SIE para o ambiente web, a exemplo 
de outros processos, como o sistema de afastamentos, substituição de chefias e o portal do professor.

Este trabalho limitou-se a propor um modelo de ferramenta de TIC para auxiliar no processo de compras da UFSM, não abordando o desenvolvimento, a implantação, e a implementação da ferramenta proposta na Instituição onde este estudo foi realizado. Outra limitação é a delimitação da ferramenta de TIC abordada, a qual ficou delimitada ao cadastramento das solicitações, acompanhamento da situação da solicitação e consulta ao registro de preço. Não foram abordadas as etapas posteriores ao término da licitação, como o pré-empenho e os acompanhamentos posteriores.

Como sugestões de trabalhos futuros tem-se a elaboração de uma ferramenta de TIC, baseada no ambiente web, que contemple todo o processo de compras da Instituição, do surgimento da demanda até o recebimento do objeto.

\section{Referências}

ALMEIDA, M. E. B. de. Educação à Distância no Brasil: diretrizes políticas, fundamentos e práticas. Disponível em:<http://www.ich.pucminas.br/pged/interact/viewfile.php/1/file/17/51/PDF.pdf>. Acesso em: 01 ago. 2017.

BAHIENSE, G. C. Alinhamento Estratégico de Tecnologia da Informação no Setor Público: A Oferta de Serviços Eletrônicos em Secretarias de Fazenda no Brasil. 237f. Tese (Doutorado em Administração). Fundação Getúlio Vargas, São Paulo, SP, 2002

BATISTA, E. de O. Sistemas de informação: o uso consciente da tecnologia para o gerenciamento. São Paulo: Saraiva, 2006.

BATISTA, M. A. C. \& MALDONADO, J. M. S. de V. O papel do comprador no processo de compras em instituições públicas de ciência e tecnologia em saúde (C\&T/S). Revista de Administração Pública, Rio de Janeiro, 42 (4), 681-699, 2008.

BERTAGLIA, P. R. Logística e gerenciamento da cadeia de abastecimento. 2. Ed. São Paulo: Saraiva, 2009.

BOND, M. T. Práticas profissionais na gestão pública. Curitiba: Ibpex, 2007.

BRASIL, Presidência da República. Decreto n 5.450, de 31/05/2005. Diário Oficial da União, Brasília, DF, 31 mai. 2005. Disponível em <http://www.planalto.gov.br>. Acesso em 20 mar 2016.

BRASIL, Presidência da República. Lei n 8.666, de 21/06/1993. Diário Oficial da União, Brasília, DF, 21 mai. 1993. Disponível em <http://www.planalto.gov.br>. Acesso em 10 mar 2016.

BRASIL, Presidência da República. Lei n 10.520, de 12/07/2002. Diário Oficial da União, Brasília, DF, 12 jul. 2002. Disponível em <http://www.planalto.gov.br>. Acesso em 25 mar 2016.

CAIA, I. M. S.; DE LAIA, M. M. A implantação do sistema eletrônico de informações no Centro de Serviços Compartilhados da Secretaria de Estado de Planejamento e Gestão de Minas Gerais. In: Encontro da Associação Nacional de Pós-Graduação e Pesquisa em Administração, 2018, Curitiba. Anais...Curitiba: ANPAD, 2018.

CALDAS, E. de L. \& NONATO, R. S. Compras públicas e promoção do desenvolvimento local. Revista do Serviço Público. Brasília, 64 (4), 465-480, 2013.

DA COSTA, C. G. A. Desenvolvimento e Avaliação Tecnológica de um Sistema de Prontuário Eletrônico do Paciente, Baseado nos Paradigmas da World Wide Web e da Engenharia de Software. 2011. 288p. Dissertação (Mestrado em Engenharia Elétrica) - Universidade Estadual de Campinas, Campinas, 2001. 
AVALIAÇÃO DA FERRAMENTA DE TECNOLOGIA DA INFORMAÇÃO E COMUNICAÇÃO (TIC) UTILIZADA NO PROCESSO DE COMPRAS EM UMA IFES: PROPOSTAS DE MELHORIAS

DIAS, M. A. P. Administração de materiais: uma abordagem logística. 4 ed. São Paulo: Atlas, 2008.

FERNANDES, C. C. C. Abrangência, inserção e impacto transformador dos sistemas de compras eletrônicas na administração pública - análise do siasg/Comprasnet. Revista do Serviço Público. Brasília, 56 (2), 195216, 2005.

GOTO, M. M. M.; RAMOS, A. M. Portais das Universidades Federais Brasileiras: uma análise a partir das cartilhas do e-PWG. In: Encontro de Administração da Informação, 2013, Bento Gonçalves. Anais... Bento Gonçalves: ANPAD, 2013.

LAUDON, K. C.; LAUDON, J. P. Sistemas de Informação Gerenciais. 9. ed. São Paulo: Pearson Prentice Hall, 2010.

LEMOS, A.; MAMEDE, J.; NÓBREGA R.; PEREIRA S.; MEIRELLES, L. Cidade, tecnologia e interfaces. Análise de interfaces de portais governamentais brasileiros. Uma proposta metodológica. Revista Fronteiras estudos midiáticos $\mathrm{VI}(2)$ : 117136, julho/dezembro, 2004.

KENSKI, V. M. Educação e Tecnologias: o novo ritmo da informação. Campinas: Papirus, 2007.

KNOPLOCK, G. M. Manual de Direito Administrativo: teoria, doutrina e jurisprudência. 6. ed. Rio de Janeiro: Elsevier, 2012

MARTINS, P. G. \& ALT, P. R. C. Administração de materiais e recursos patrimoniais. 2. ed. São Paulo: Saraiva, 2006.

MOTA, T. B.; DE OLIVEIRA, A. M. C. J.; DE FREITAS, A. F. Desenvolvimento e uso de um software de gestão sob a ótica das dimensões organizacional, tecnológica e humana em empresas públicas. Navus. Florianópolis, v. 6, n. 3, p. $70-87$, jul/set. 2016.

NETTO, F. S. Modernização da Administração Pública Brasileira com o uso da Tecnologia da Informação: fatores críticos de sucesso. Franca: Ribeirão Gráfica e Editora, 2007.

O'BRIEN, J. A. Sistemas de informação e as decisões gerenciais na era da Internet. 2. ed. São Paulo: Saraiva, 2006.

QUEIROZ, F. C. B. P., et al. Aplicação de modelo de mensuração da satisfação dos usuários de um sistema de informação acadêmico: estudo de caso na Universidade Federal do Rio Grande do Norte. In: XVII Colóquio Internacional de Gestão Universitária. 2017, Mar del Plata. Anais...Mar del Plata: Universidad Nacional de Mar del Plata, 2017. Disponível em: <https://repositorio.ufsc.br/xmlui/bitstream/handle/123456789/181034/101_00101. pdf? sequence=1\&isAllowed=y>. Acesso em: out 2018.

REYNOLDS, H. \& KOULOPOULOS, T. Enterprise knowledge has a face. Intelligent Enterprise. v. 2, n. 5. Disponivel em: <http://www.intelligententerprise. com/db_area/archives/1999/993003/feat1.shtml> Acesso em: mai 2016.

REZENDE, D. A. \& ABREU, A. F. Tecnologia da informação aplicada a sistemas de informação empresariais. 2. ed. São Paulo: Atlas, 2001.

SALDANHA, C. Introdução à Gestão Pública. São Paulo: Saraiva, 2006.

SANTOS, L. R. L. dos. Fiscalização de contratos. Cadernos ENAP, Brasília, 36, 82p, 2013.

SILVEIRA, H. F. R. da. Governo e sistemas de informação: de arquipélago a continente. Revista do Serviço Público, Brasília, 53(2), 117-149, 2002.

TRIDAPALLI, J. P. \& FERNANDES, E. \& MACHADO, W. V. Gestão da cadeia de suprimento do setor público: uma alternativa para controle de gastos correntes no Brasil. Revista de Administração Pública, Rio de Janeiro, 45(2), 401-433, 2011.

UNIVERSIDADE FEDERAL DE SANTA MARIA. Proplan. Santa Maria, 2014. Disponível em <http://w3.ufsm.br/ proplan>. Acesso em 17 mar 2016. 